\title{
Augmented Reality Technologies
}

\author{
Abdul Rahman Farid Kamal Heikal
}

Postgraduate Researcher, PhD, Faculty of Fine Arts, Alexandria University

\section{Research problem :}

Can modern technology be used through the effect of augmented reality in advertising in different fields ?

Does augmented reality present a difference from the real reality by adding stimuli that work to attract the recipient?

I found, as a researcher, presented in the advertising process and methods of presentation, which resulted in a desire to facilitate the process of finding distinctive characteristics of what will be advertised in three more ways than their counterparts in real reality .

research importance :

The use of modern technological media and keeping pace with the times, and what will result in showing Egypt in a more modern way through its use of 
modern methods and keeping pace with the times and here lies the importance of research in that augmented reality has become of great importance in different fields, which leads to an increase in the economic value and thus helps to attract the public Towards the advertised product, as it contributes to increasing the national income of countries in general and Egypt in particular .

\section{research aims :}

Highlight the changes that have been developed in the means of advertising and methods of presentation .

Developing propaganda in Egypt using augmented reality technology . Illuminating the use of aesthetic and artistic values in the development of propaganda using augmented reality .

\section{Types of augmented reality :}

\section{On the basis of location distinction :}

Digital media provides users with smartphones or mobile devices with GPS positioning, and multimedia (such as text, graphics, audio files, video clips, and 3D shapes) provides the physical environment with academic or navigational information related to the location (Meehan, Michael, et, 2003,p 12)

\section{On the basis of the vision :}

Providing users with digital media after a certain thing has been photographed by the mobile phone camera or portable smart devices such as (Q.R codes, multi-dimensional images, and markers) so that the camera can capture and distinguish it to display the information associated with it ( Dunn, Andrea. et,2016, p 27) 
Augmented Reality Features :

- Mixes the real and the assumption, in a real environment.

- Interactive at the time of using it.

- Three-dimensional 3D.

- Provides clear and accurate information.

- The ability to enter information in an easy and effective way.

- The possibility of interaction between two parties, such as: (teacher and learner).

- Although simple to use, it provides powerful information.

- Make complex procedures easy for users.

.Cost effective and easily deployable (Fritzsch, Bernd, et. 2011,pp. 16-26) . -

\section{How does augmented reality work?}

Augmented reality works by adding unrealistic layers to the actual reality, and this is certainly done through tools capable of creating this addition and this mixing, among them, on top of which is the smartphone. (Philip, Kortum, 2008.p 124)

Reality is captured through phone cameras, and through the main processor and graphics processor, digital models are processed through special applications, so that this mixture is finally displayed through the phone screen, and with different augmented reality tools, whether it is a smartphone, helmet, or special glasses, no The principle on which the technology is based varies (Papadakis, Giorgos, et., pp. 581-584. ACM, 2011)

\section{How to test augmented reality technology?}

To discover the world of augmented reality, the first and easiest way to test it is to use a smartphone with the specifications that most above-average phones currently have, such as: camera, high-resolution screen, graphics processor, and 
Accelerometer Sensor, which is a sensor that is able to detect your movement of the phone and then track this movement

Laptops and desktops can also be used to test augmented reality via webcams, but this method is highly ineffective due to the difficulty of moving such devices, the lack of motion sensors and the limited support applications. (McAnally, Ken I., and Russell L. Martin. P.14)

\section{The use of augmented reality in three vital areas, namely :}

Adding information digitally to the physical world, such as adding directions on the road, or adding customer reviews digitally to a restaurant front ( NASA.,Robonaut 2 Getting His Space Legs, 2011,pp.12-16).

Creating an interactive digital environment different from real reality and merging them together like what happened in Pokémon GO (Philip, Kortum,2008.p 124)

Enhancing physical figures with digital ones, which is the simplest and easiest image that Snap chat used to use in its effects (Parallax, 2013, p 10) .

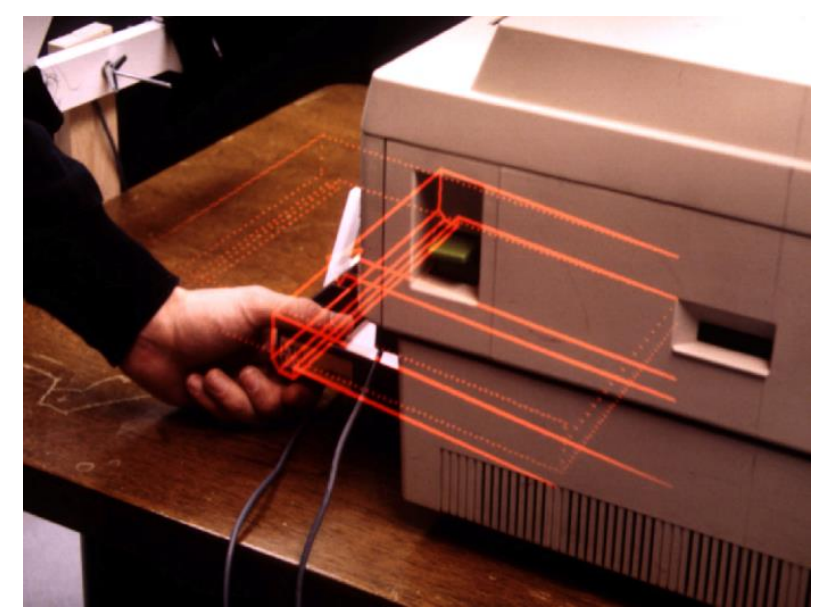

KARMA (Knowledge Based Augmented Reality for Maintenance Assistance)

First knowledge augmented reality app that enables users with monitors on the head to view printer maintenance instructions, Columbia University. 
In 1993, Feiner and others introduced KARMA, a knowledge-based augmented reality merging system. This system was able to infer appropriate instruction sequences for repair and maintenance procedures (Hollerer, tobias, 2017, p7 )

In 2008, Schönfelder and Schmalstieg proposed a system based on augmented reality technology, the Planar device, which is an augmented reality screen on wheels with external tracking. It provides real-time interactive contrast check for whole industrial facilities .

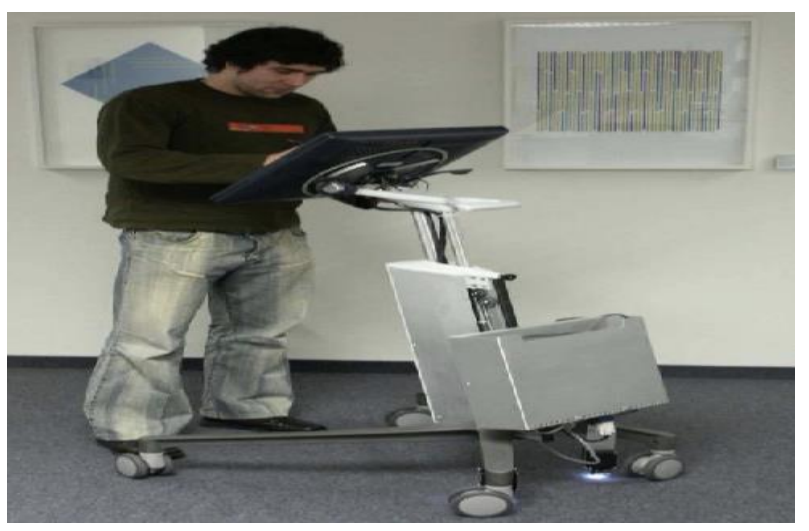

Planar device (2)
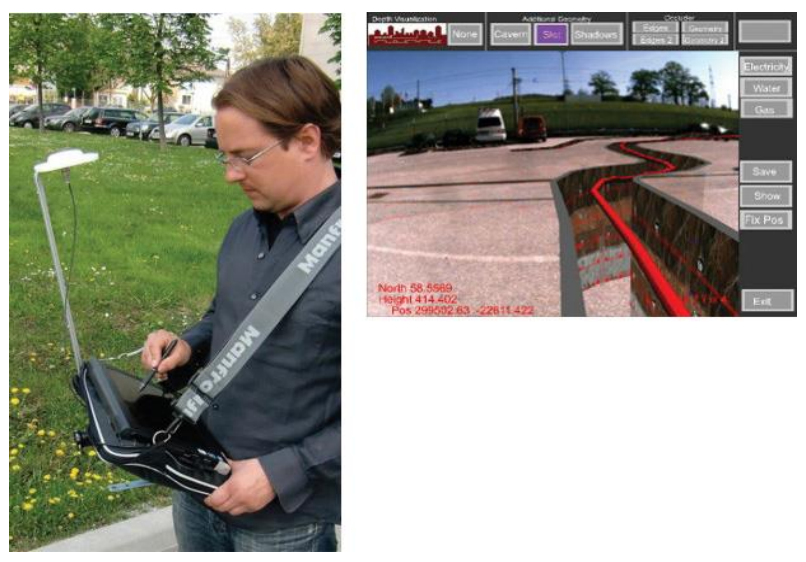

GEO AR device

(3)

Public utility companies rely on geographic information systems (GIS) to manage underground infrastructure, such as telecommunications lines or gas pipelines. In different circumstances, it may require accurate identification of the locations of the underground assets. For example, construction managers are legally obligated to obtain information about underground infrastructure so that they can avoid any damage to these structures during excavation operations. Likewise, determining the cause of the service interruption or updating 
of outdated GIS information often requires on-site inspection. In all of these cases, providing an AR preview of the target site, the preview derived from the geographic information system and directly from the location can greatly improve the accuracy and speed of outside work (Hollerer, tobias, 2017, pp.15-16) .

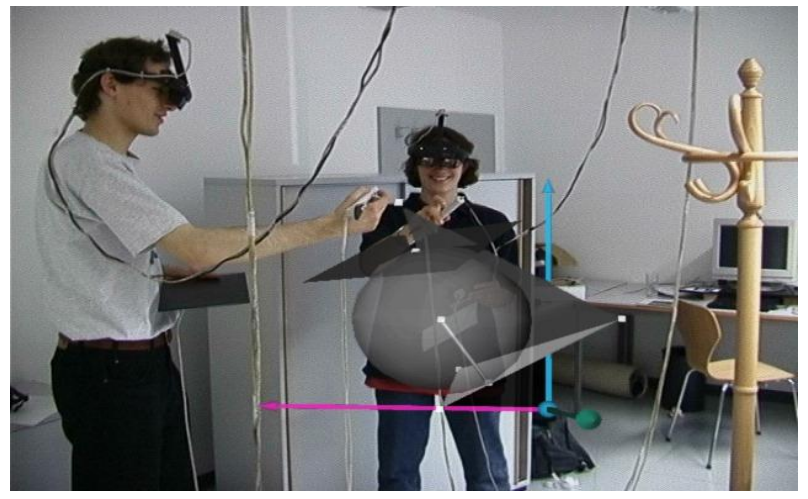

One of the applications of the Studierstube is teaching engineering through augmented reality to

high school students

Schmalstieg performed in 1996. With the development of the Studierstube, the first AR system augmented reality. With this system, many users can experience seeing the objects converted into 3D objects. Each HMD user has head-mounted screens and can see optically identical holograms, tested successfully with high school students (Hollerer, tobias, 2017, p.9)

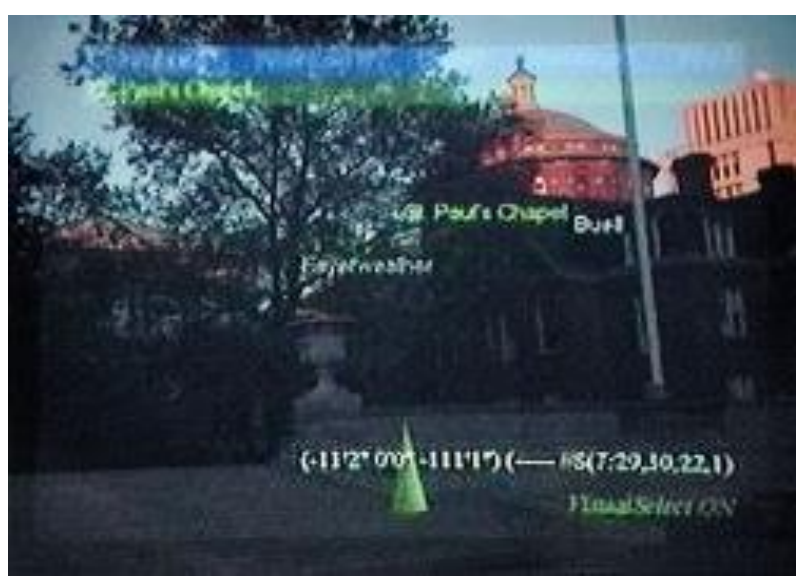

Using augmented reality as a guide to navigating campus - Columbia University 1990 (5) In the same year, Germany's Federal Ministry of Education and Research launched a $€$ 21 million program for the industrial company AR, called ARVIKA (Augmented Reality for 
Development, Production and Services). More than 20 research groups in industry and academia have worked to develop advanced AR systems for industrial applications, particularly in the German auto industry. This program raised awareness of AR worldwide in professional societies and it is followed by many similar programs designed to enhance the industrial application of the technology .

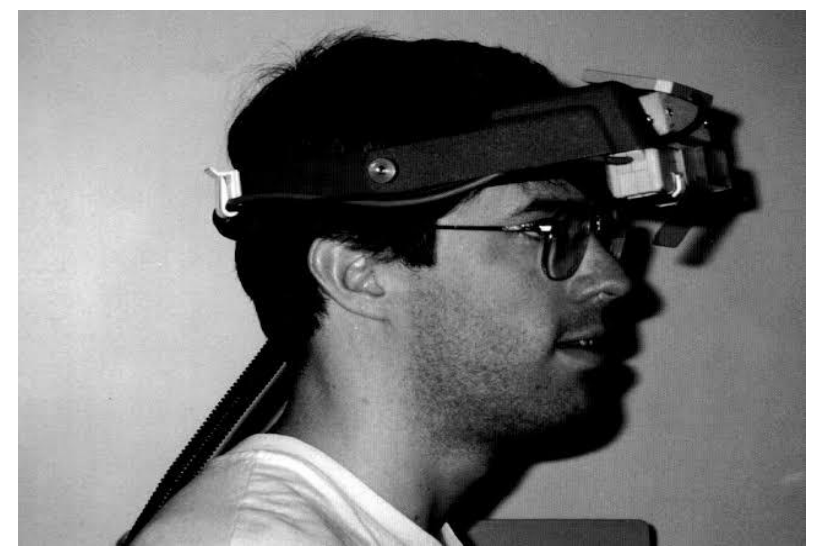

A head-mounted screen used in the architectural field (Columbia University) in 1993 (6) When talking about the topic of augmented reality in the construction sector, Stéphane Côté of Pentley Systems says: “One day, we might see all construction workers equipped with advanced and integrated smartphones in their clothing, as they will follow detailed visual and verbal instructions from a construction app that carefully coordinates the work of All site (personnel (Peddie, Jon, 2017, p90)

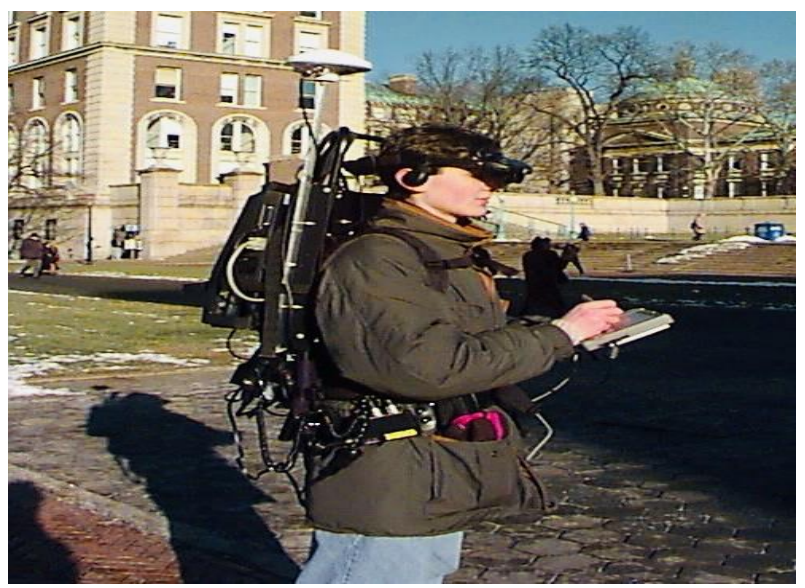

The first augmented reality touring machine in the tourism field (7) 
In 1997, Feiner developed the first cellular augmented reality system, a touring machine, at Columbia University. The tour cruiser uses a head-mounted screen device with a GPS and directional tracking system. You provide 3D graphics for the smartphone. This system consists of a backpack that holds a computer and various sensors and a primary tablet for input. (Hollerer, Tobias, 2017, p10)

Thus, augmented reality continues to evolve from laboratory experience to military and then industrial applications, as it has empowered military, industrial and scientific users .who have specific and urgent needs

Science fiction has been a precursor to future technologies, and there are many examples of augmented reality that artists, writers, and scientists might have imagined before the existence of technology in order to achieve such devices, environments, and ideas taken that may not be widely available (or were not available at all). However, work continues to .make AR real (Aukstakalinis.steve.2017, p12)

Augmented reality may be seen as a visual system, and as augmenting what we see with information and graphics. However, the auditory senses can also benefit from augmented reality, as this can be very useful if one of the users is blind, or partially blind (Peddie, Jon, 2017, p104)

Augmented reality systems take us to the next level in computer interfaces, and they are unlike any you may be familiar with from the past. Before there was augmented reality

Wearable augmented reality displays, in which virtual data and images overlap, may merge with the real world, with new operating systems enabling a new type of spatial computing that will require a new user interface. However, augmented reality systems can be quite complex, along with the challenge of being lightweight, portable, and noticeable, and of course affordable .

With augmented reality system, we become part of the computer environment, rather than just being a separate outside observer with limited interaction. This, in turn, would revolutionize computer interfaces and interactivity. And because it is a revolution, all the nuances and opportunities may not be understood yet, and they will not be understood as well 
for a long time as developers and users experiment with this new way of communicating with the computer (Niu, E., 2016, p14)

Augmented reality may fully merge the real image with simulated or synthetic images and information shared in the wearer's line of sight. Almost everyone has seen Princess Leia in Star Wars as a 3D projected image from R2D2 robot. These photos were amazing in 1977, and now we are able to bring them to life with augmented reality. Instead of science fiction .light, however, the image can be viewed with augmented reality (Peddie, Jon, 2017, p40)

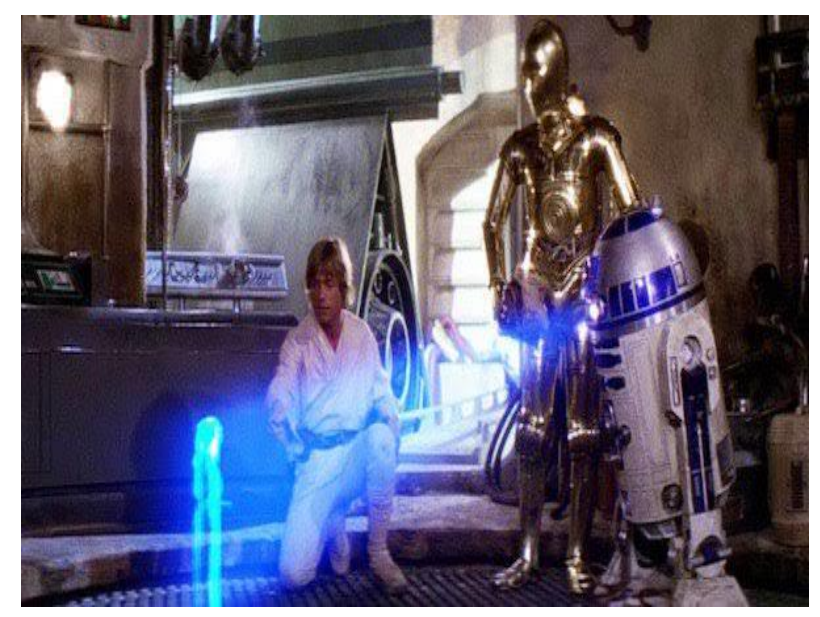

Princess Leia in the 1977 Star Wars movie, a 3D image projected from the R2D2 robot (8)

The idea of having large amounts of simultaneous, instant and timely information, or that the information is constantly available to you, is a dream that we have all dreamed of for a long time. The miracle of augmented reality is that we took our pocketbooks and magically linked them to massive amounts of information and data. And we fed them with our movements and our locations in real time, and we were able to reach what we need from them. "Be careful who you might want." If you have too many labels in a scene or too many items, it becomes confusing and difficult to read .

Without limits, your AR device can be flooded with unwanted information, ads, messaging, .reminders, and intrusions (Peddie, Jon, 2017, p15) 


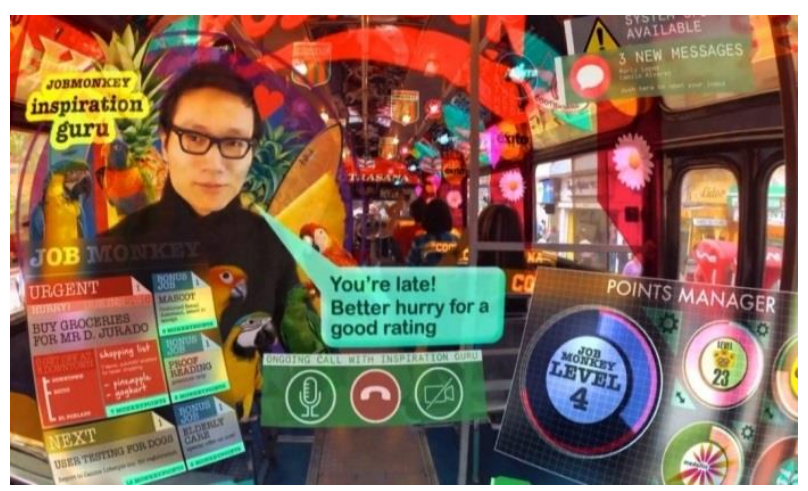

Keiichi Matsuda's vision for information flow as one package (9)

\section{The Promise of Augmented Reality :}

Augmented reality devices will do more than just give us tips and product visualizations. Rather, augmented reality will be integrated with body sensors in real time to monitor our temperature, oxygen level, glucose level, heart rate, EEG (Electroencephalogram), which is a test program that searches for problems related to electronic activities in the brain, and other important parameters ( Srdjan, Maksimovic, 2014, pp. 617-621) .

\section{Augmented Reality Building Skills :}

To design, build and manufacture an augmented reality device, a company must have a wide range of experts: engineers, scientists, technologists, clinicians, mathematicians and managers. They should understand and know how to deal with (Hollerer, Tobias, :2017, p33)

Sound technology

Camera technology

Display technology

Geometric mathematics and trigonometry

Image processing techniques

Manufacturing engineering

Optics and Optometry 
Physiology

\section{Energy management}

Software engineering, operating systems, APIs, drivers, computer graphics, and game engines .

In augmented reality, a computer uses position and motion sensors and directional sensors and algorithms to determine the position and direction of the camera. The augmented reality technology then renders the 3D graphics as they appear from the camera's perspective, overlaying the computer-generated images over the user's view of the real world. Augmented reality is made possible by the use of a smartphone, helmet, tablet, computer, or glasses. Virtual reality only uses a head-mounted screen, and does not provide any direct view of the real world; However, the glasses used can be as simple as Google Cardboard:

(Aukstakalinis.steve.2017, p 114)

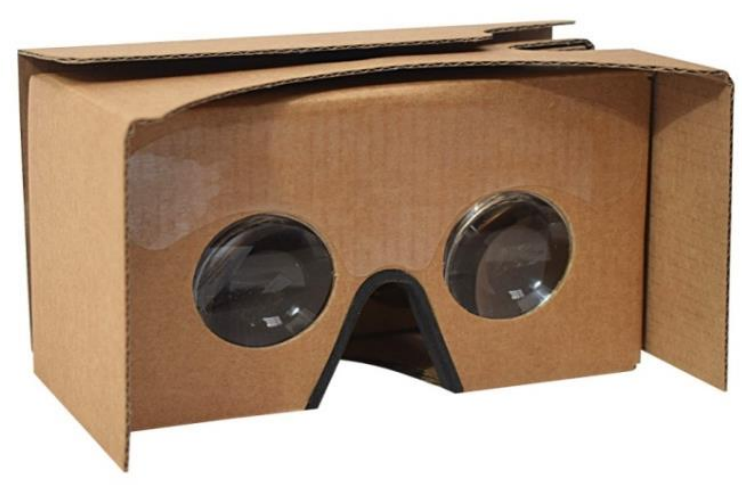

Google Cardboard glasses

A visual solution is critical to successfully integrating interactive and real scenes

Types of interactive modern ads, some of which are based on the use of augmented reality technology :

The development of road advertisements has extended even further by relying on the interaction in the advertisement, whereby the designer depends on changing the lighting condition on the interaction between the advertiser and the participant in the communication, so the lighting unit remains closed until someone passes from under it, and its condition changes to the lighting position . 


\section{Interactive mobile ads :}

Mobile services have been implemented globally, enabling customers and agencies to interact directly with consumers through advertising the road. The mobile phone services are new services that also allow consumers to interact with the road advertisement to find out more information about the nature of the product, or to obtain some information such as finding the nearest store to get the product .

We find that the application of this technology through advertising the road will now enable advertisers to be able to update the content of the advertising message based on the variables and measure the degree of interaction of the audience with the content of the advertising message

\section{Advantages of Interactive Road Advertising via Mobile Phone : -}

A cultural image and advertising scene draws the attention of tourists to Egypt's use of modern advertising methods. (William F Arens, David H. Schaefer, 2009-p.377)

\section{Disadvantages of an interactive mobile road ad : -}

- It may not be suitable for some elderly people.

Temporary suspension of power failure -

(William F Arens, David H. Schaefer, 2009-p.379) 

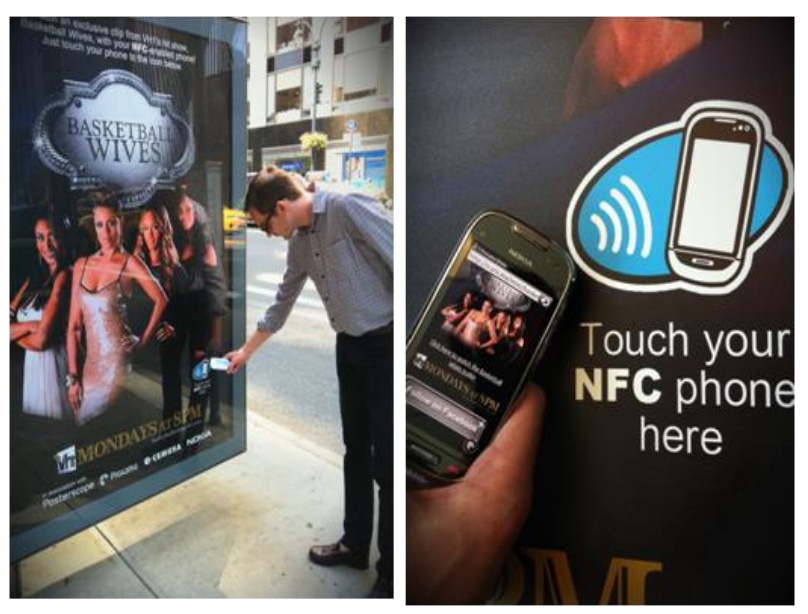

(11) Interactive road advertisement via mobile phone

www. Clearchanneloutdoor.com

\section{Giant Television Advertising Screen :}

The brand and product in this type of road advertisement has a high degree of visibility in high traffic areas, and these giant screens are surrounded by large frames, with .high quality and design

It is similar to a television screen, but it is large in size and contains an electronic memory that bears a number of ads.( William F Arens, David H. Schaefer, 2009, p. 378 )

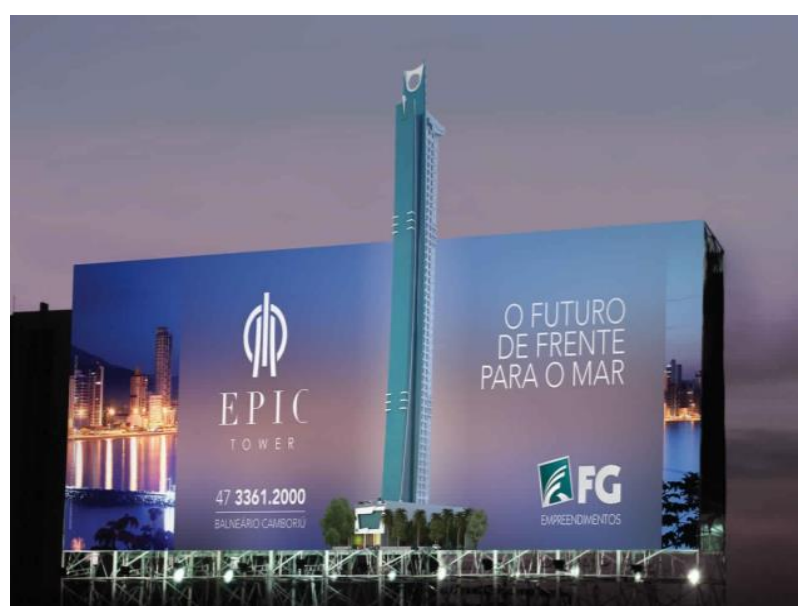

(12) Road ads on giant TV screens

https://aqualiteoutdoor.com/big-screen-led-signs-billboards 
INTERNATIONAL JOURNAL OF

ARTIFICIAL INTELLIGENCE AND EMERGING

TECHNOLOGY

\section{Outdoor LED Screen :}

A type of new road advertisement and this type of road advertisement are on television screens and are of high quality to meet all the visual needs of outdoor display. (William F Arens, David H. Schaefer, 2009,p.379)

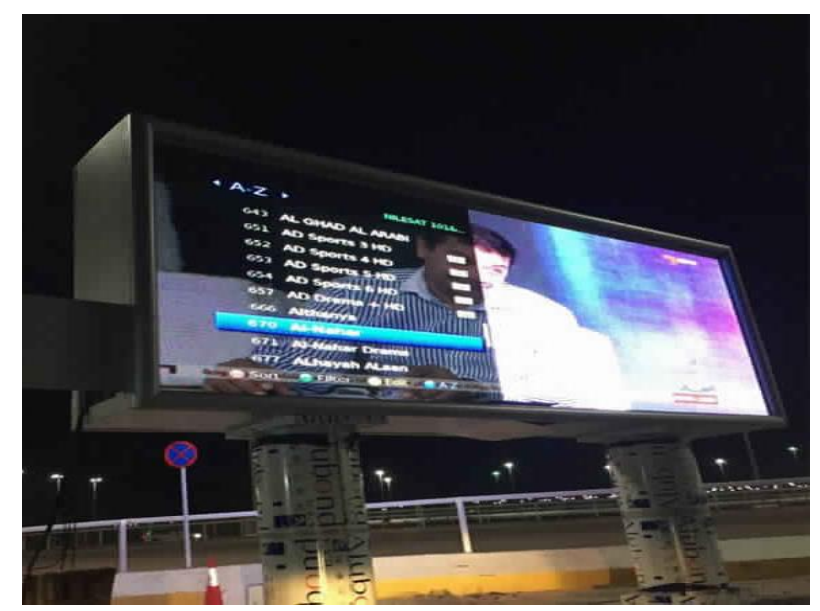

(13) Road advertisement on giant LED screens

https://www.indiamart.com/proddetail/outdoor-led-display-screen-14586318048.html

It has the advantage of working under bright direct sunlight. It also consumes less energy and is weatherproof, and these screens can provide all kinds of images with high quality and are distinguished from television screens by allowing us to use so-called curved screens .

examples of some tourist streets and buildings in different regions of the world that rely on augmented reality technology for advertising and tourism advertising

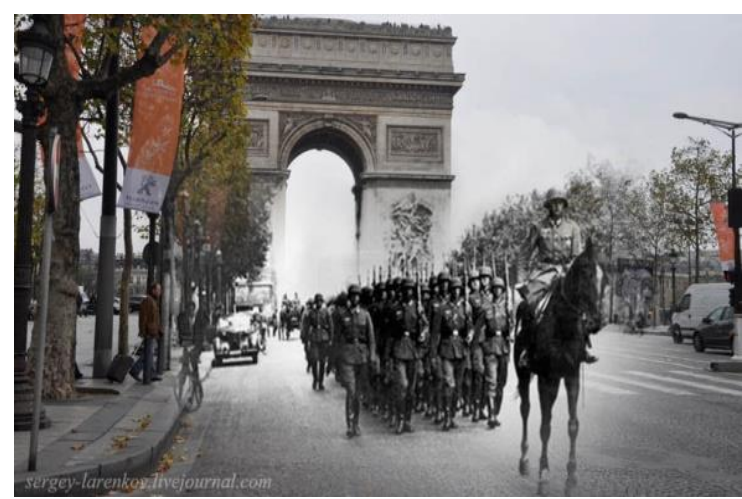

(14) Demonstrates the use of augmented reality in the Arc de Triomphe, France https://www.zumoko.com/travel-and-tourism-with-augmented-reality 


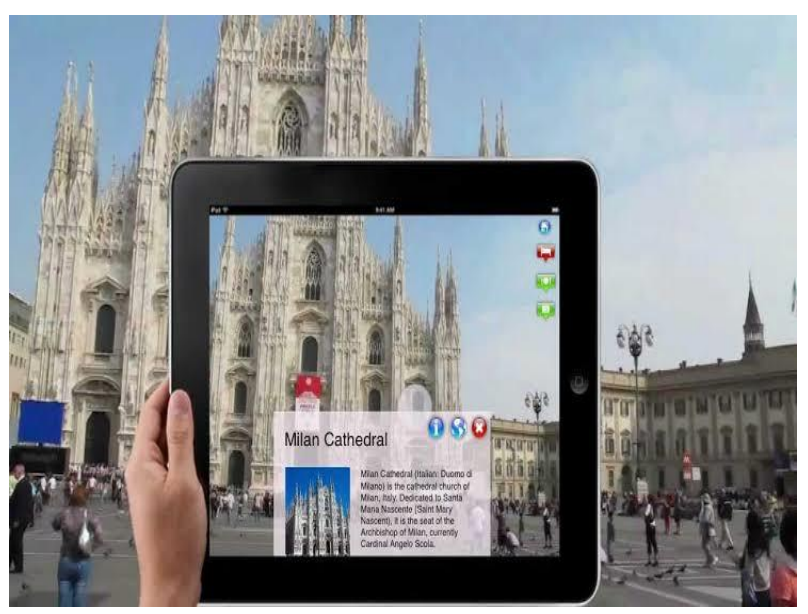

(15) Demonstrates the use of augmented reality in Milan Cathedral, Italyhttps://thinkmobiles.com/blog/augmented-reality-tourism

\section{Art and augmented reality :}

Art galleries and museums at home and abroad have been experimenting with using augmented reality since early 2010 to promote exhibitions by combining what is on the gallery wall with photos while the visitor is watching through their mobile device 
INTERNATIONAL JOURNAL OF

\section{ARTIFICIAL INTELLIGENCE AND EMERGING}

TECHNOLOGY

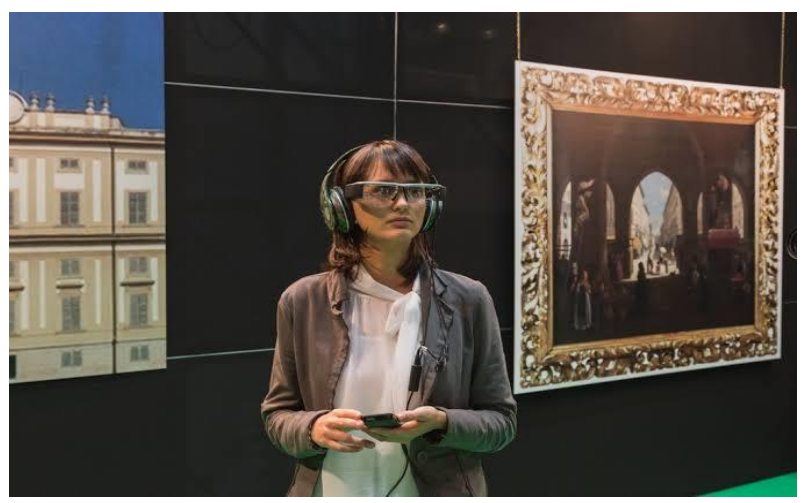

A woman wears augmented reality glasses to be able to see things that are not present at the (16)

International Exhibition of Information and Communication Technology in Milan

(Peddie ,Jon, 2017,p137)

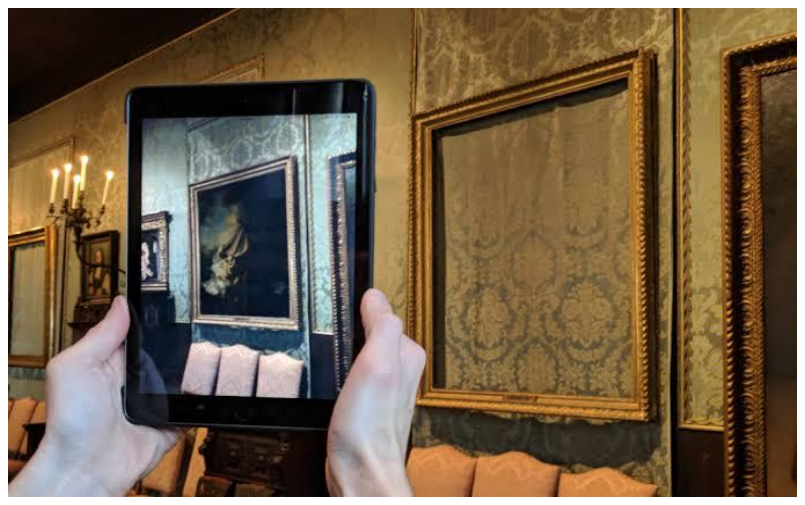

The Stolen Arts Museum is an exhibition of currently stolen or lost works (17)

There is also the Augmented Reality Museum of Stolen Art that was started in 2014 by Ziv Schneider at NYU's ITP. Peddie, Jon, 2017, p13

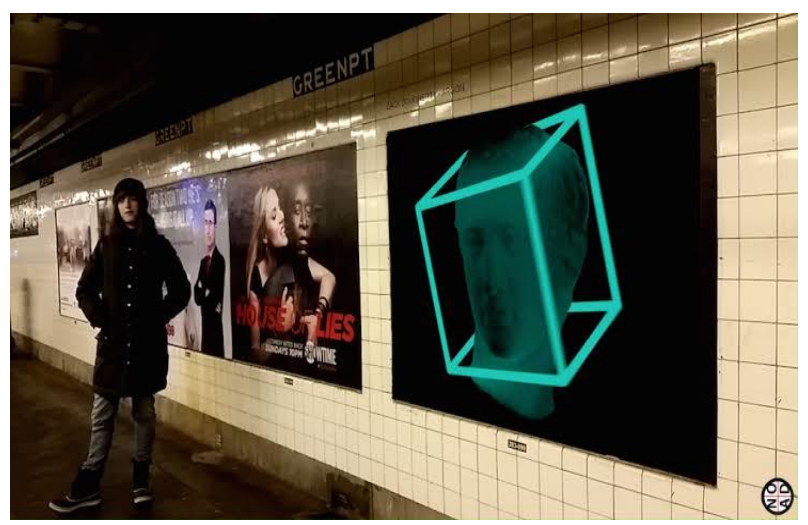

NO AD superimposed art via augmented reality on the New York subway (18) 
INTERNATIONAL JOURNAL OF

ARTIFICIAL INTELLIGENCE AND EMERGING

TECHNOLOGY

In 2015, a group of students created the NO AD project, an augmented reality project to make New York subway stations full of movie posters, product ads, as they became works of art (through augmented reality (Peddie, Jon, 2017, p139)

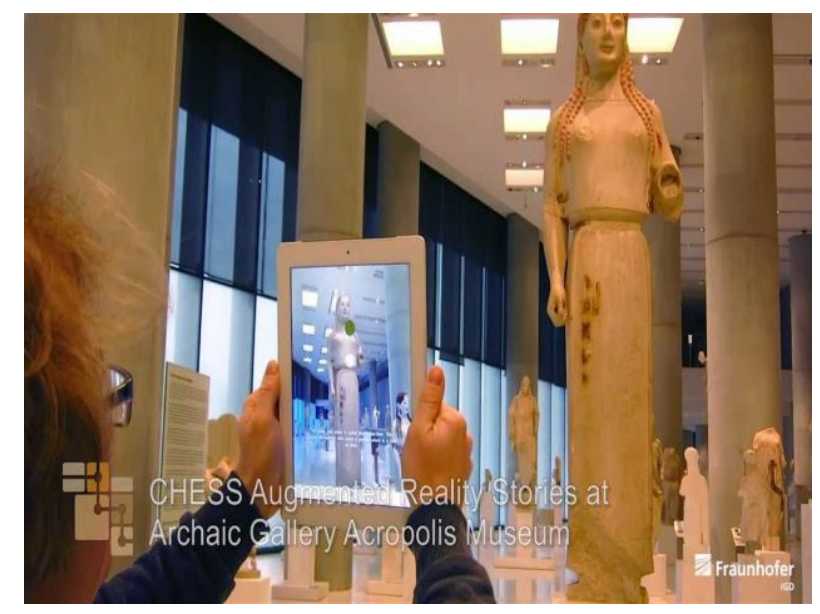

The Acropolis Museum (19)

https://www.viator.com/es-VE/tours/Athens/Acropolis-of-Athens-and-New-Acropolis-Museum-Tour/d4962906NEWACROPOLIS

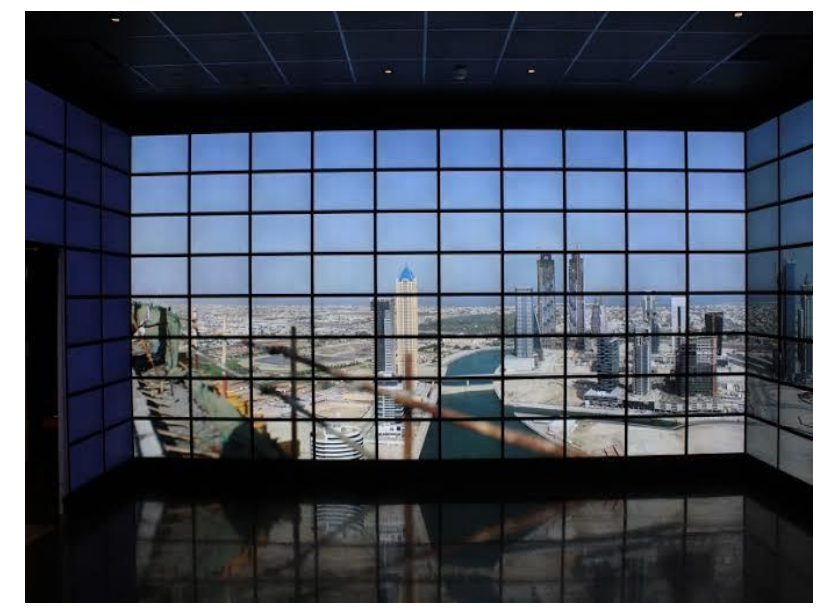

(These are called Stony Brook University's Augmented Reality Caves.Peddie „Jon, 2017,p44) (20) 


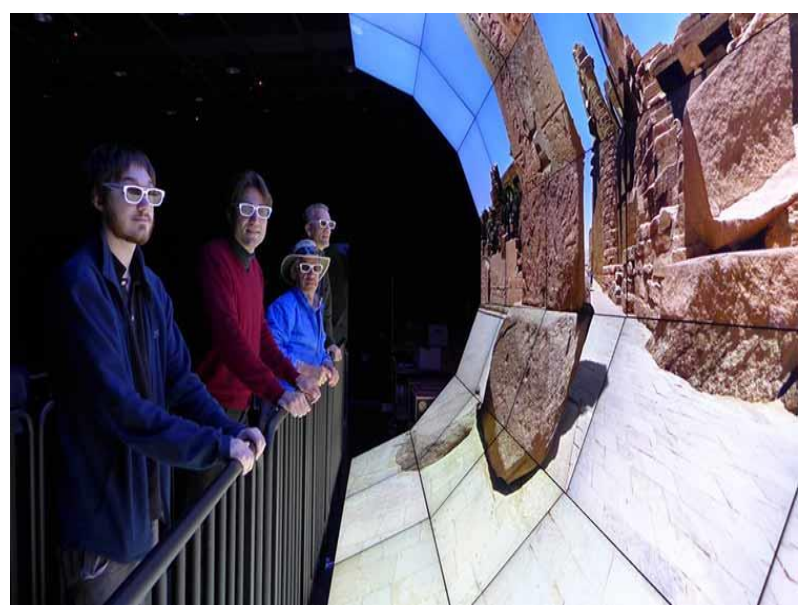

San Diego, California_شكل (21) يطلق على هذه الثاشات مسمى الكهوف التى تعمل بتقنية الواقع المعزز بجامعا (Peddie ,Jon, 2017,p44)

\section{Education and augmented reality:}

Augmented reality will transform the entire education sector from training to implementation

Augmented reality applications can complement the standard study curriculum. By drawing, video, text and audio in a student's textbook in real time. Textbooks, flashcards, and other educational reading materials are all means of obtaining additional and supplementary information, and a way to keep textbooks popular and up-to-date. There are early examples using pages containing tags, which, when scanned with an AR device, may generate supplemental information for the student which may be presented in multimedia form (Mashita, T., Yasuhara, H., Plopski). , A., Kiyokawa, K., and Takemura, H. 2013, pp. 275276)

There are applications that can be used in higher education to help students understand concepts of physics, mathematics, engineering, electrical, chemical, or mechanical engineering. These processes are positive learning processes where students learn to learn using technology. For example, in chemistry, augmented reality can help students visualize the spatial structure of a molecule and interact with an interactive model that is shown in an AR display, which could be a smartphone or tablet. Augmented reality has also been used in physiology to visualize the different systems of the human body. (Sweeney, C, FragosO, V., .Hollerer, T., and Turk, M, 2014, pp. 16-17) 
This is what is being done now through the distribution of a tablet device by the Egyptian Ministry of Education to students .

Elementary school children can learn through experiences and visuals designed to help them learn. Children will be able to better understand the solar system when using augmented reality devices and be able to view it in 3D. Also to teach anatomy, teachers can visualize bones and organs using augmented reality. Languages can be taught using translation applications and supplementary information .

One of the first real-life training systems for teaching welding was developed by Soldamatic in 2013 in Huelva, Spain. Where students work in a real welding environment, while using all the real elements used in the workshops (welding torches, welding helmets, workpieces, etc.) and using augmented reality technology to make all these elements interact, and to draw the effects of welding graphics generated by the computer, And provide realistic (training experiences for the welding process. Peddie, Jon, 2017, p94 .

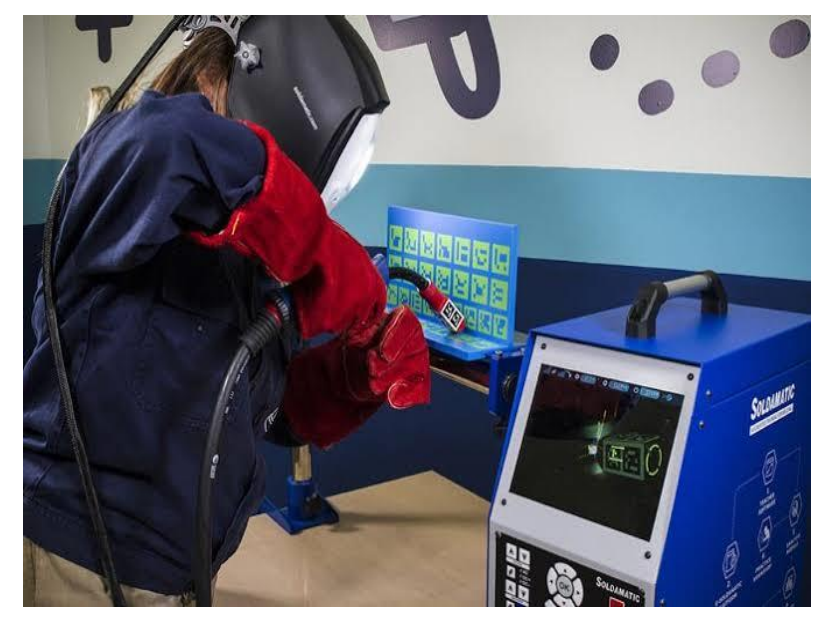

Soldamatic augmented welding training (22)

In 2013, researchers at Carlos III University in Madrid developed a prototype of augmented reality-based smart glasses to improve classroom interaction. When the teacher wears the augmented reality glasses, he can see above the students' heads, that is, the symbols that may indicate the state of mind of the students at any particular time, that is, to show, for example, when they have a question or whether they have understood or not understand the point he is explaining 
The prototype developed by Madrid researchers is controlled by gestures, captured with a Microsoft Kinect camera. The system, called the Augmented Lecture Feedback System, requires professors to wear augmented reality goggles to see symbols above students' heads (and facilitate communication between students and professors. Peddie, Jon, 2017, p96

\section{The study of topography by using Ar Sandbox technology}

It is a set of cameras that scan surfaces and project three-dimensional 3D images as for the eyes of their viewers as if you are seeing an interactive layer above the real world .

The US National Science Foundation has funded the AR SAND BOX program with the aim of developing earth science concepts among university students, and this is done through a real sandbox and a MICROSOFT KINECT 3D camera, allowing the creation of topographic models that enhance the cognitive field of students and researchers in the field of geosciences Peddie, Jon, 2017 , p43

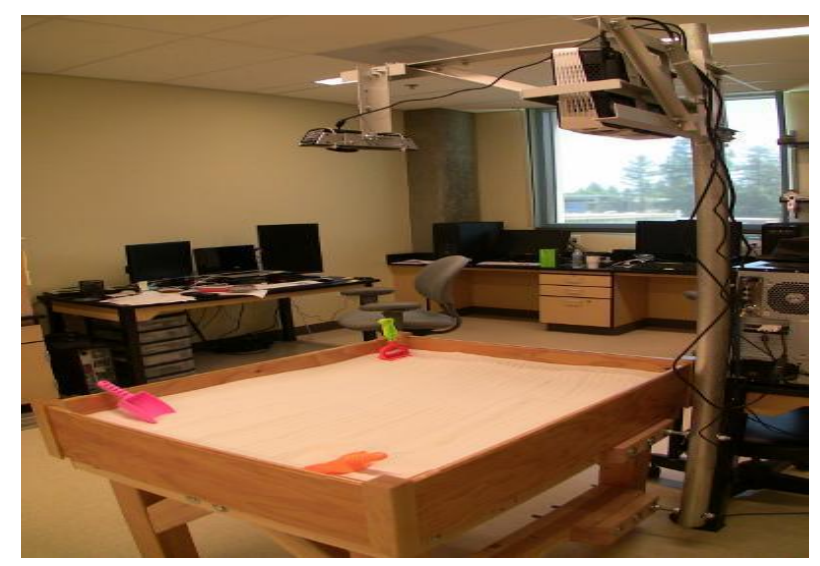

Explains the use of the Microsoft Kinect camera, which helps in studying topography (23)

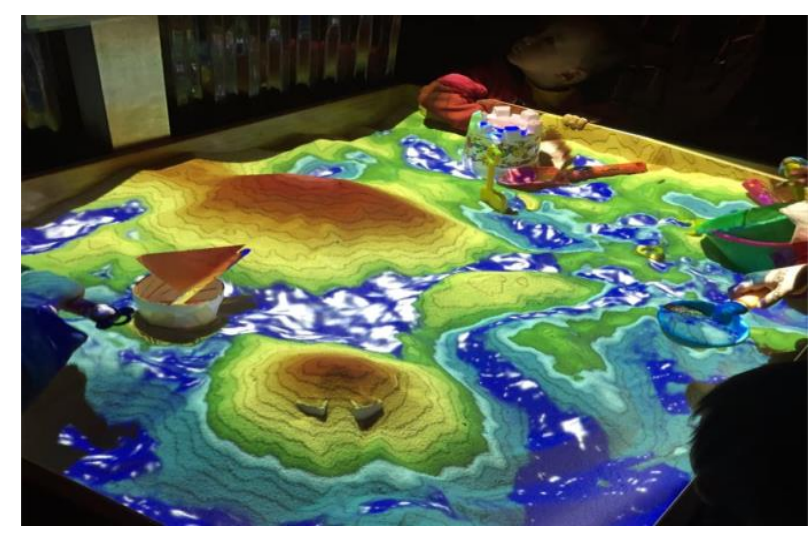


Explains the use of the Microsoft Kinect camera, which helps in studying topography (24)

\section{References :}

1. Arth, C., Pirchheim, C., Ventura, J., Schmaistieg, D., and Lepetit, V. (2015) Instant outdoorlocalization and SLAM initialization from 2.50 maps. IEEE Transactions on Visualization and Computer Graphics (Proceedings ISMAR) .

2. Bachmann, E. R., and McGhee, R. B. (2003) Sourceless tracking of human posture using small inertial/magnetic sensors. Proceedings of the IEEE International Symposium on Computational Intelligence in Robotics and Automation (CIRA), 822829.

3. Barba, E., Maclntyre, B., and Mynatt, E. D. (2012) Here we are! Where are we? Locating mixed reality in the age of the smartphone. Proceedings of the IEEE 100,4, 929-936.

4. Baricevic, D., Hollerer, T., Sen, P., and Turk, M. (2014) User-perspective augmented reality magic lens from gradients. Proceedings of the ACM Symposium on Virtual Reality Software and Technology (VRST).

5. Barron, J.T., and Malik, J. (2015) Shape, illumination, and reflectance from shading. 1EEETransac-tions on Pattern Analysis and Machine Intelligence.

6. Benko, H., Wilson, A. D., and Zannier, F. (2014) Dyadic projected spatial augmented reality. Proceedings of the ACM Symposium on User Interface Software and Technology (UIST).

7. Braun, A., and McCall, R.(2010) User study for mobile mixed reality devices. Proceedings of the Joint Virtual Reality Conference, EUROGRAPHICS Association.

8. Buker, T. J., Vincenzi, D. A., and Deaton, J. E. (2012) The effect of apparent latency on simulator sickness while using a see-through helmet-mounted display: Reducing 
apparent latency with predictive compensation. Human Factors 54,2, Sage Publications.

9. Bunnun, P., and Mayol-Cuevas, W. W. (2008) OutlinAR: An assisted interactive model building system with reduced computational effort. Proceedings of the IEEE and ACM International Symposium on Mixed and Augmented Reality (ISMAR).

10. Sweeney, C, FragosO, V., Hollerer, T., and Turk, M. (2014) gDLS: A scalable solution to the generalized pose and scale problem. Proceedings of the European Conference on Computer Vision (ECCV), Springer.

11. Tabin G, M. Chen, and L. Espandar. "Cataract Surgery for the Developing World." Current Opinion in Ophthalmology, 19 (2008): 55-59.

12. W.Dwn and A.M. , 1988, Bordon, Advertising, It, s role in modern marketing 4 th. Ed Jllinois, the Dyden press..

13. William F Arens, David H. Schaefer, Michael Weigold: (2009) Essentials of contemporary advertising - second edition - McGraw - Hill Higher education New York.

14. Hollerer, Tobias, 2018, .Augmented reality, princieles and practice, springer ISBN 978-3-319-54501-1- ebook, libray of congress control number 2017936981.

\section{Websites :}

15. www.Clearchanneloutdoor.com.

16. Augmented reality in: Encyclopedia Britannica 2010. http://www.britannica.com/technology/ augmented-reality [13 May 2016].

17. https://gamesalr'resco.com/2008/12/04/9-movies-that-will-inspire-your-nextaugmented-reality-experience/

18. Dunn, Andrea. NASA Is Laser-Focused on Deep Space Communication." NASA JSC International Space Station Program Science Office. October 6,2015. Retrieved March 27,2016 from http://www.nasa.gov/mission_pages/station/research/news/comm_delay_assessment.

19. Ford Motor Company. "Ford Reduces Production Line Injury Rate by 70 Percent for Its More Than 50,000 'Industrial Athletes."' Media Release, July 16,2015. Retrieved 
INTERNATIONAL JOURNAL OF

ARTIFICIAL INTELLIGENCE AND EMERGING

TECHNOLOGY

December 28,2015 from

https://media.ford.com/content/fordmedia/feu/fr/fr/news/2015/07/16/ford

20. Ford Motor Company. "New Virtual Lab Improves Ford Global Vehicle Quality." Media Release,December 12,2013. Retrieved December 27, 2015 from https://media.ford.com/content/

21. Jacobi, J. "4D BIM or Simulation-Based Modeling." Apr, (2011). Structuremag.org. Retrieved November 1,2015 from http://www.structuremag.org/wpcontent/uploads/2014/08/C-lnSights-Jacobi-Aprill 11.pdf. McKinney,

22. Niu, E. (2016, October 14). Apple, Inc. Is more i iterested in augmented reality than virtual reality. The Molely Fool, http://www.fool.com/investing/2016/10/14/apple-incis-more-interested-in-augmented-reality.aspx

23. Virtually Better, Inc. "Telemental Health VR Project: Virtual Iraq Overview" (2008). Retrieved September 2015 from http://www.virtuallybetter.com/af/virtualiraq_overview.html.

24. Mahmoud, Ahmed, Abdel Azem, Virtual Reality Technology and its Role in Advertising Field, International Journal of Artificial Intelligence and Emerging Technology, Vol.1, No.1, 2018, pp. 14-38. 